\title{
Humidity sensor failure: a problem that should not be neglected
}

\author{
Y. Liu ${ }^{1,2}$ and N. Tang ${ }^{3}$ \\ ${ }^{1}$ Numerical Weather Prediction Center, China Meteorological Administration, no. 46 South Zhongguancun Street, \\ Haidian District, Beijing 100081, China \\ ${ }^{2}$ National Meteorological Center, China Meteorological Administration, no. 46 South Zhongguancun Street, Haidian District, \\ Beijing 100081, China \\ ${ }^{3}$ College of Atmospheric Science, Nanjing University of Information Science and Technology, no. 219 Ningliu Road, \\ Nanjing, 210044, China
}

Correspondence to: Y. Liu (liuyan@cma.gov.cn)

Received: 23 March 2014 - Published in Atmos. Meas. Tech. Discuss.: 4 July 2014

Revised: 1 October 2014 - Accepted: 10 October 2014 - Published: 25 November 2014

\begin{abstract}
The problem of abnormally dry bias induced by radiosonde humidity sensor failure in the low and midtroposphere is studied based on the global operational radiosonde relative humidity observations from December 2008 to November 2009. The concurrent humidity retrievals from the FORMOSAT-3/COSMIC radio occultation mission are also used to assess the quality of the radiosonde humidity observations. It is found that extremely dry relative humidity are common in the low and mid-troposphere, with an annual globally averaged occurrence of $4.2 \%$. These lowhumidity observations usually exist between 20 and $40^{\circ}$ latitude in both the Northern Hemisphere and Southern Hemisphere, and from heights of 700 to $450 \mathrm{hPa}$. Winter and spring are the favored seasons for their occurrence, with a maximum fraction of $9.53 \%$ in the Northern Hemisphere and $16.82 \%$ in the Southern Hemisphere. The phenomenon does not result from natural atmospheric variability, but rather humidity sensor failure. If the performance of humidity sensors is not good, low-humidity observations occur easily, particularly when the radiosonde ascends through stratiform clouds with high moisture content. The humidity sensor cannot adapt to the huge change of the atmospheric environment inside and outside stratiform clouds, resulting in sensor failure and no response to atmospheric change. These extremely dry relative humidity observations are erroneous. However, they have been archived as formal data and applied in many research studies. This may seriously undermine the reliability of numerical weather prediction and the analysis of weather and climate if quality control is not applied before using these data.
\end{abstract}

\section{Introduction}

Radiosonde observation is an important means of obtaining upper-air temperature, pressure, moisture content and wind observations. It has been used operationally for over 70 years. Although the performance of radiosonde humidity sensors and the accuracy of observational data have gradually being improved, data quality remains an issue, particularly in the upper troposphere and lower stratosphere, where sensors cannot detect the high relative humidity inside cirrus clouds. A number of studies, including analysis of long-term observations, and international inter-comparison experiments of different radiosonde systems organized by the World Meteorological Organisation intercomparison campaigns, have demonstrated that humidity observations have large errors, especially in the upper troposphere and stratosphere (Nash et al., 2010; Li et al., 2012). These errors are associated with the limited performance of the humidity sensor under low temperature and low-humidity conditions and other errors; e.g., radiation dry bias, time-lag errors, sensor icing and contamination et al. (Wang et al., 2003; Miloshevich et al., 2006; Vömel et al., 2007; Nash et al., 2010; Bian et al., 2011). Although radiosonde humidity sensor technology has been improving, problems remain (Wang et al., 2002; Wolfgang et al., 2008). For example, some operational radiosonde hygrometers using carbon hygristors fail to respond to humidity changes in the upper and sometimes the middle troposphere (Wang et al., 2003). 
Recently, a new issue has come to light from the Chinese L-band radiosonde relative humidity observations (Tang et al., 2014). Relative humidity profiles from this type radiosonde often indicate a very thick dry layer in the lower troposphere, with low relative humidity values $(<2 \%)$ at a given height (or above the given height) and with no response to humidity changes, sometimes until the end of the sounding (Fig. 1a). Occasionally, some profiles can recover partly or entirely with height (Fig. 1b). Although low relative humidity observations of less than $10 \%$ are common in the troposphere (Spencer and Braswell, 1997; Zhang et al., 2003; Wang et al., 2010), Zhang and Chen (2010) suggested that such dramatic changes of the relative humidity from the Chinese L-band radiosonde system do not comply with the atmospheric stratification law. Tang et al. (2014) analyzed dry biases of Chinese L-band radiosonde humidity profiles observed in the lower troposphere, and hypothesized that the dry biases were likely the result of humidity sensor failure. They further showed that the dry bias phenomenon depended on both the performance of the humidity sensor and the cloud types encountered. The humidity sensor often fails if the sounding instrument goes through deep and thick clouds, most of which are stratiform clouds with high water vapor and an obvious dry layer accompanied by atmospheric temperature stratification.

The occurrence of dry bias in the Chinese L-band radiosonde system due to humidity sensor failure reached $12.63 \%$ in the survey period (Tang et al., 2014). This is a serious problem that should not be neglected by the numerical weather prediction community. Do other countries' operational radiosonde systems exist in the abnormal dry phenomenon in the low and mid-troposphere like the Chinese L-band radiosonde system? If so, what are their causes and distribution characteristics? This is the aim of this paper. The remainder of the paper is organized as follows: Sect. 2 describes the data and methods employed in the study; Sect. 3 surveys global operational radiosonde humidity observations for extremely thick dry biases; Sect. 4 presents a comparison between radiosonde relative humidity observations, radio occultation humidity retrieval production and analysis data; Sect. 5 describes the possible causes of the relative humidity observation dry biases; Sect. 6 presents the discussion and conclusion.

\section{Data and method}

The radiosonde data used in this paper span from December 2008 to November 2009, and are obtained from the Global Telecommunication System. After excluding stations with fewer than five observations, a total of 844 radiosonde stations carrying out 451283 soundings comprise the sample. The method proposed by Tang et al. (2014) is adopted to survey the new issue of humidity observation. Namely, if the thickness of a relative humidity profile with a value of
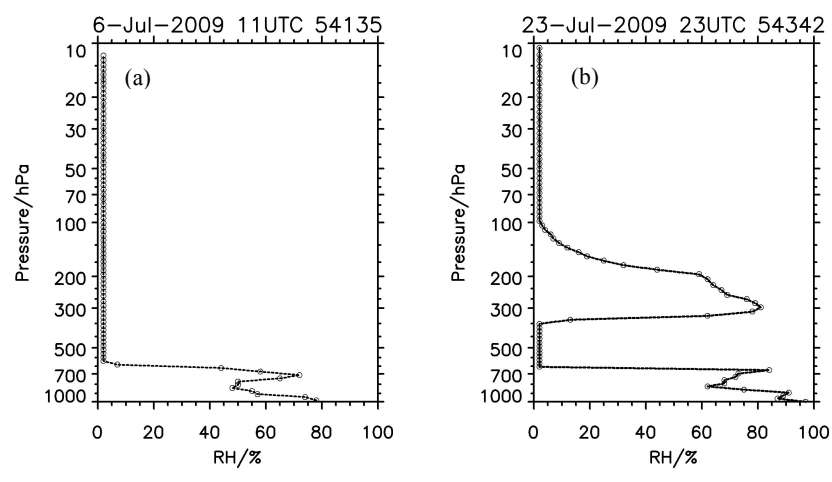

Figure 1. Two examples of abnormally dry profiles of relative humidity from the Chinese L-band radiosonde system. Source: Tang et al. (2014).

less than $5 \%$ continuously appears greater than $200 \mathrm{hPa}$ below the $300 \mathrm{hPa}$ height, we assume that the dry bias of the humidity profile is affected by the sensor failure. The height under $300 \mathrm{hPa}$ is chosen to emphasize the fact that we are investigating a new issue of humidity observation biases in the low and middle troposphere, instead of the well-known issue of dry bias in the high troposphere.

The radio occultation (RO) data of the Constellation Observation System of Meteorology, Ionosphere and Climate (COSMIC) program (Anthes et al., 2008) and the ERAInterim reanalysis results (Dee et al., 2011) of the European Centre for Medium-Range Weather Forecasts (ECMWF) model are intercompared for the study period. The matching method between $\mathrm{RO}$ and radiosonde data also follows the method implemented by Tang et al. (2014). The time window for the match is $3 \mathrm{~h}$ before and after the radiosonde observation time, and the space window is in a $250 \mathrm{~km} \times 250 \mathrm{~km}$ square grid at the center of the radiosonde release point. If the RO falls within the grid, radiosonde matching is confirmed. If multiple RO profiles are matched at the same time, we select the nearest RO profile.

The Magnus saturation vapor pressure equation is used to calculate the saturation vapor pressure of the RO observation (WMO-NO, 2012):

$e_{s}=\left\{\begin{array}{l}6.112 \times \exp \left(\frac{17.62 \times T}{243.12+T}\right) \times F(p) \text { if }(T \geq-45) \\ 6.112 \times \exp \left(\frac{22.46 \times T}{272.62+T}\right) \times F(p) \text { if }(T<-45)\end{array}\right.$,

where $T$ is temperature in ${ }^{\circ} \mathrm{C}$, and $F(p)$ is the enhancement factor related to atmospheric pressure $p$ in $\mathrm{mb}$, defined as

$F(p)=1.0016+3.15 \times 10^{-6} \times p-\frac{0.074}{p}$.

Vapor pressure is then converted to relative humidity:

$\mathrm{RH}=\frac{e}{e_{s}} \times 100 \%$.

The unit of vapor pressure is $\mathrm{mb}$. 
To compare these data, radiosonde data are converted from a geopotential height to a geometric height coordinate using the following equation:

$z=\frac{a \times \bar{g} \times z_{\mathrm{g}}}{g_{0}(\varphi, 0) \times a-\bar{g} \times z_{\mathrm{g}}}$,

where $z$ represents the geometric height in meters, $z_{\mathrm{g}}$ represents the geopotential height with the unit of geopotential meters, $a$ is the radius of the earth at $6371137 \mathrm{~m}$, the gravitational constant $\bar{g}=9.80665 \mathrm{~m} \mathrm{~s}^{-2}$, which is the average at a $45^{\circ}$ latitude at sea level, and $g_{0}(\varphi, 0)$ is the acceleration of gravity at latitude $\varphi$ at sea level, defined as

$$
\begin{aligned}
& g_{0}(\varphi, 0)=9.80620 \\
& \quad \times\left(1-0.0026442 \times \cos 2 \varphi+0.0000058 \times \cos ^{2} 2 \varphi\right) .
\end{aligned}
$$

Finally, we use cubic spline interpolation to interpolate the radiosonde data to vertical layers with a resolution of $100 \mathrm{~m}$; i.e., the same resolution as the $\mathrm{RO}$ data.

\section{Results}

\subsection{Global distribution of humidity sensor failures}

Table 1 shows the number and percentage contribution of failed relative humidity observations for all four seasons. A total of 18609 failed relative humidity observations among 447021 profiles are recorded between December 2008 and November 2009, and the percentage of failure is approximately $4.17 \%$ worldwide. Table 1 indicates that humidity sensor failure may occur at any time, but it is more probable during winter and spring for both hemispheres, with the highest percentages during winter $(9.53 \%)$ in the mid-latitude region of the Northern Hemisphere, and in the mid-latitude region of the Southern Hemisphere (16.82\%). In the survey, 211 out of 844 radiosonde stations have no failed observations; these stations are mainly located in the high-latitude regions of the Northern Hemisphere and in tropical regions.

Figure 2 shows the number of failed relative humidity sensor observations for each radiosonde station during the period of the survey. Different color dots correspond to the number presented in the color bar, and the black hollow circles indicate that no humidity sensor failure is observed. The failed observations mainly occur in the latitudes between 20 and $40^{\circ}$ for both hemispheres. The number of failed observations is high in China, the United States, Australia, western Europe and on the eastern coast of South America. The problem in China is particularly serious with failures of 218 out of the 720 sensors released on radiosondes from the Dalian station. However, humidity sensor failure is rare in the tropical and high-latitude regions.

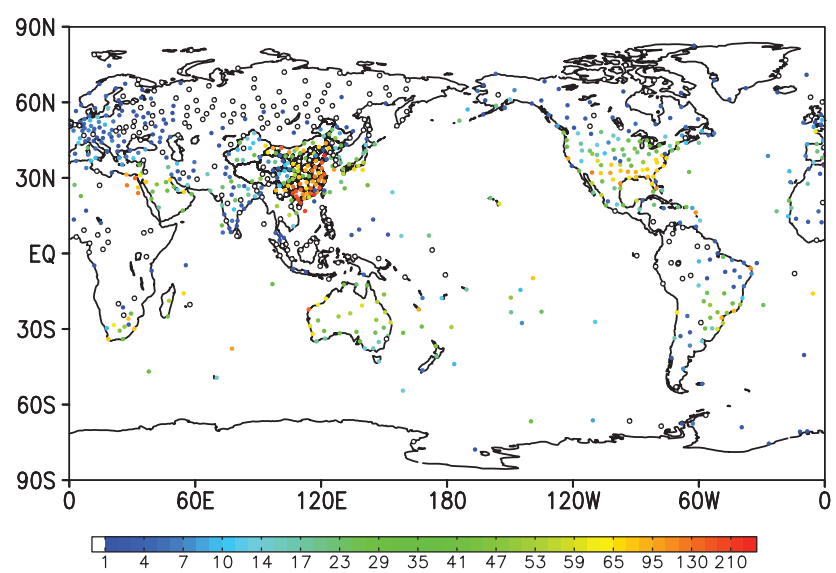

Figure 2. The total number of failed relative humidity observations for each operational radiosonde station from December 2008 to November 2009. The colored dots correspond to values indicated by the color bar, and the black open circles denotes no humidity sensor failure observation.

\subsection{Characteristics of seasonal variation and vertical distribution}

Figure 3 presents the statistics of relative humidity sensor observation failure for all four seasons. As shown in the images, failed relative humidity observations occur mainly during spring and winter. Failed observations are less likely during the summer, but gradually increase during autumn. This trend is observed at a latitude close to $30^{\circ}$ in both the Northern Hemisphere and Southern Hemisphere.

Figure 4 shows the height and total station number that satisfy the failure criterion. The height of most failed observations is between 700 and $450 \mathrm{hPa}$, peaking at 700 to $650 \mathrm{hPa}$, followed by 500 to $450 \mathrm{hPa}$. Failed observations may be seen under $900 \mathrm{hPa}$; this indicates that humidity sensor failure may occur at very low heights.

\section{Comparison with COSMIC/GPS RO data}

Table 2 lists the number of observations, failed observations and matched failed observations obtained by RO and three widely used operational instruments. We calculate the bias and standard deviation for the failed, normal and total observations. Figure 5a shows the statistical results for all radiosondes across the entire year. Figure $5 b-d$ compares the results obtained by three instruments with COSMIC/GPS IDVAR retrieval data. The number of failed observations is small on a global basis, thus resulting in the near superposition of the "normal observations" line (blue) and "all observations" line (red). Figure 5a also shows that the bias between normal and all observations is about $\pm 5 \%$ under an $8 \mathrm{~km}$ height; thus, although COSMIC data have errors, the data are still in line with the World Meteorological Organization requirements on observation uncertainty and are suitable 
Table 1. Statistics of total and failed relative humidity observations from December 2008 to November 2009 for global observations $\left(90^{\circ} \mathrm{S}-90^{\circ} \mathrm{N}\right)$, low latitudes $\left(20^{\circ} \mathrm{S}-20^{\circ} \mathrm{N}\right)$, mid-latitudes of the Northern Hemisphere $(\mathrm{NH})\left(20^{\circ} \mathrm{N}-60^{\circ} \mathrm{N}\right)$, and mid-latitudes of the Southern Hemisphere (SH) (20 S-60 S). DJF: December, January, February; MAM: March, April, May; JJA: June, July, August; SON: September, October, November.

\begin{tabular}{|c|c|c|c|c|c|c|c|c|}
\hline \multirow[b]{2}{*}{ Season } & \multicolumn{2}{|r|}{ Global } & \multicolumn{2}{|c|}{ Low latitudes } & \multicolumn{2}{|c|}{ Mid-latitudes of NH } & \multicolumn{2}{|c|}{ Mid-latitudes of SH } \\
\hline & Total & Failed & Total & Failed & Total & Failed & Total & Failed \\
\hline DJF (200 812-200 902) & 109592 & $5996(5.47 \%)$ & 13748 & $734(5.34 \%)$ & 48345 & $4609(9.53 \%)$ & 7327 & $363(4.95 \%)$ \\
\hline MAM (200 903-200 905) & 111496 & $4402(3.95 \%)$ & 14040 & $332(2.36 \%)$ & 48905 & $3374(6.90 \%)$ & 7492 & $503(6.71 \% \%)$ \\
\hline JJA (200 906-200 908) & 112174 & $3837(3.42 \%)$ & 15242 & $572(3.75 \%)$ & 48863 & $1852(3.79 \%)$ & 7242 & $1218(16.82 \%)$ \\
\hline SON (200 909-200 911) & 113100 & $4374(3.87 \%)$ & 15824 & $499(3.15 \%)$ & 49442 & $3070(6.21 \%)$ & 6654 & $563(8.46 \%)$ \\
\hline 1 year $(200812-200911)$ & 446362 & $18609(4.17 \%)$ & 58854 & $2137(3.63 \%)$ & 195555 & $12905(6.60 \%)$ & 28715 & $2647(9.22 \%)$ \\
\hline
\end{tabular}
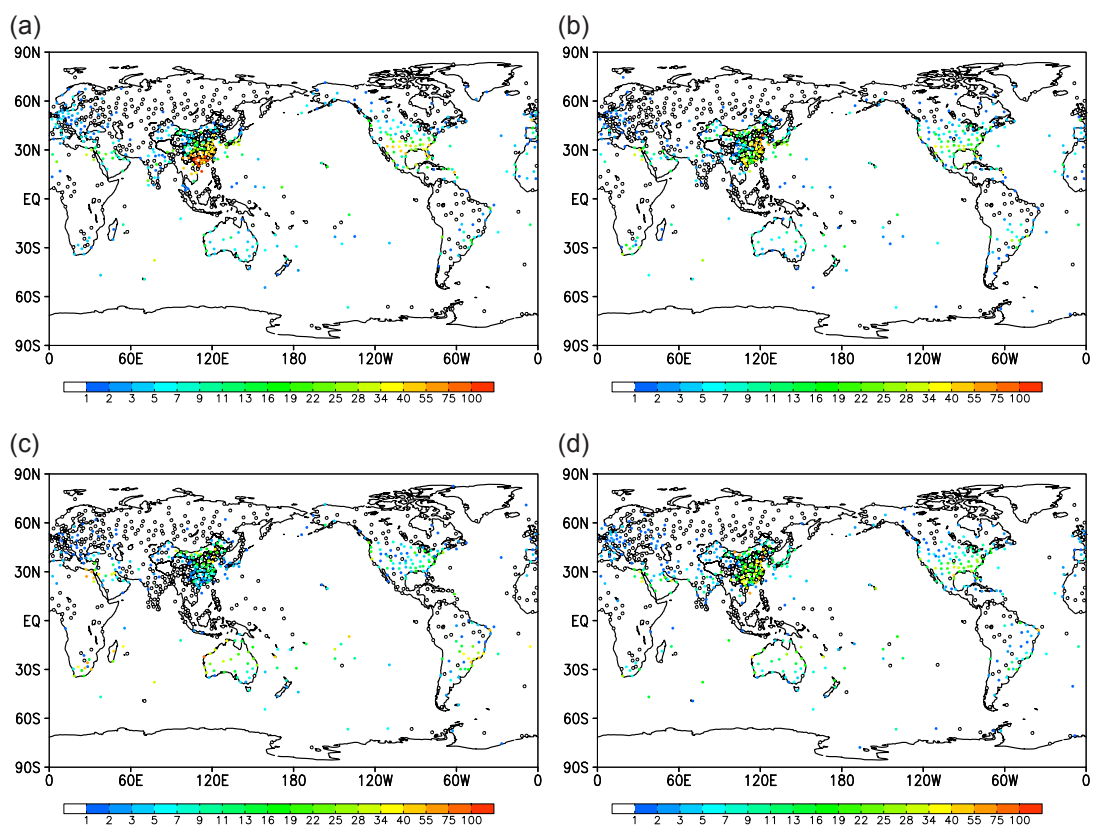

Figure 3. As in Fig. 2, but separated into four seasons: (a) DJF (December, January, February); (b) MAM (March, April, May); (c) JJA (June, July, August); (d) SON (September, October, November).

for cross-comparison. Compared with RO data, dry bias from failed observations is larger than that in normal cases and the maximum bias is beyond $-10 \%$. Figures $5 b-d$ show the similarity between the RS92, Sippican and L-band humidity sensors and the COSMIC retrieval humidity data. The dry bias of RS92 is smallest, whereas the dry bias of the Chinese L-band is larger in the entire troposphere; this result is consistent with other research findings (Li et al., 2009; Sun et al., 2011; Bian et al., 2011). There is no obvious difference between nighttime and daytime soundings when it comes to the occurrence of the humidity sensor malfunction (figure not shown).

Figure 6 illustrates two radiosonde relative humidity profiles in comparison with the ECMWF analysis and RO data from the surface to a height of $100 \mathrm{hPa}$. The radiosonde observations, RO data and analysis generally have good consistency. However, upon humidity sensor failure, the relative humidity drops quickly from high moisture to low moisture,

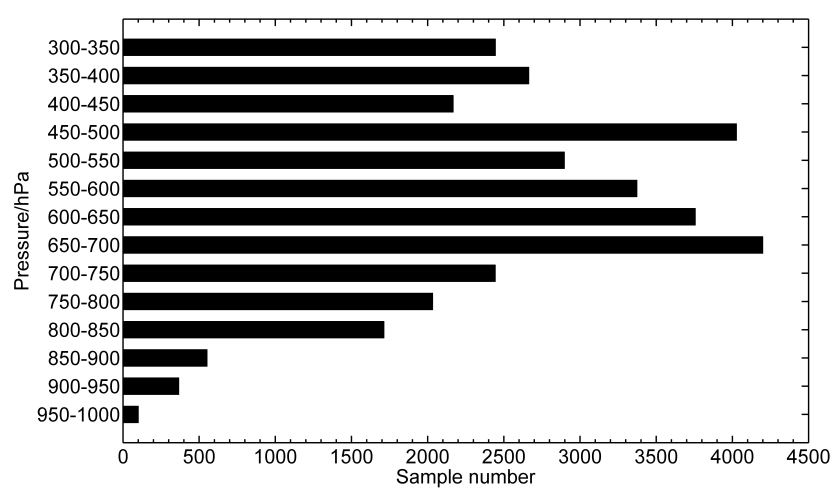

Figure 4. Vertical distribution characteristics of failed relative humidity observations from December 2008 to November 2009. 

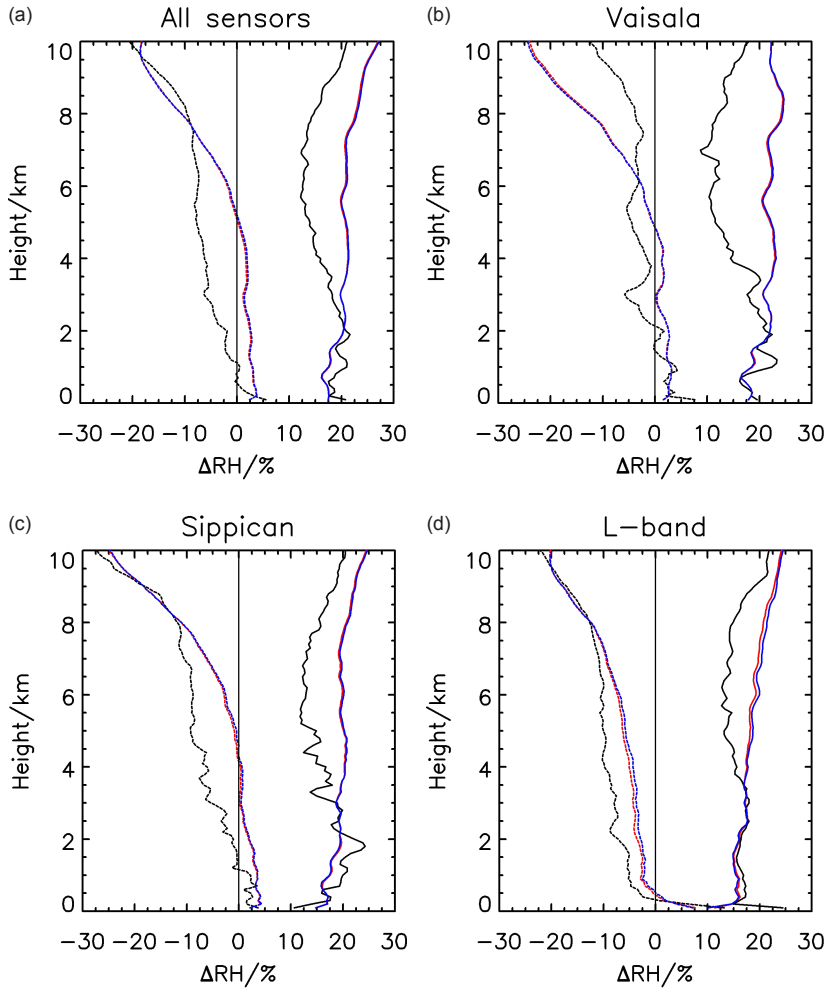

Figure 5. Bias (dashed line) and standard deviation (solid line) of the relative humidity data between the radiosonde observations and COSMIC RO retrievals. The red lines represent all observations, the blue lines represent the normal observations and the black lines represent the failed observations. Panel (a) shows the statistics for all sensors, (b) just Vaisala RS92, (c) Sippican and (d) the China L-band sensor.

and the sensor stops working entirely above a certain altitude. Although the $\mathrm{RO}$ and analysis profiles also experience a rapid decrease, the reduction is not less than $10 \%$, and the value does not remain constant. This indicates that temperature, pressure and humidity data based on 1DVAR are not subject to the sensitivity of the sensors. Sometimes, the humidity sensor partly or fully recovers as the radiosonde re-enters the clouds (Fig. 6b), including cirrus clouds, because the high moisture inside the clouds is helpful for sensor recovery. Figure 6 also illustrates that the abnormal dry phenomenon in the lower troposphere is unreasonable; it does not reflect the true state of the atmosphere. However, these data have been archived as formal records and are widely used in scientific research and services. If these data are used without correction and quality control, weather prediction and climate analysis will be significantly affected negatively. RO observations and the analysis of numerical weather prediction might provide an effective approach to correct or remedy the failed radiosonde humidity observations.
Table 2. Statistics of the total and failed relative humidity observations matched with COSMIC data for different sensors from December 2008 to November 2009.

\begin{tabular}{lrrrrr}
\hline & \multicolumn{2}{c}{ All observations } & & \multicolumn{2}{c}{ Failed observations } \\
\cline { 2 - 3 } \cline { 5 - 6 } Sensor & Total & Matched & & Total & Matched \\
\hline All sensors & 447021 & 26405 & & $18609(4.17 \%)$ & 904 \\
RS92 & 144668 & 8586 & & $5114(3.53 \%)$ & 262 \\
Sippican & 59607 & 3670 & & $3347(5.62 \%)$ & 191 \\
L-band & 61736 & 2657 & & $7796(12.63 \%)$ & 321 \\
DFM-90/97. & 9272 & 404 & & $246(2.65 \%)$ & 15 \\
Meteorit MARS & 6488 & 590 & & $8(0.12 \%)$ & 0 \\
VIZ & 6804 & 409 & & $80(1.18 \%)$ & 4 \\
Meisei & 7890 & 229 & & $22(0.28 \%)$ & 0 \\
Modem M2K2 & 8279 & 414 & & $512(6.18 \%)$ & 26 \\
\hline
\end{tabular}
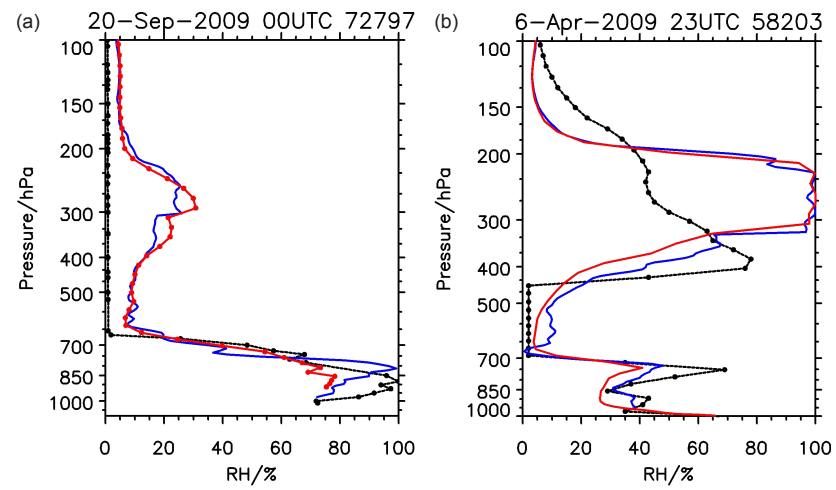

Figure 6. Comparison of the relative humidity profiles among the radiosonde (black), COSMIC retrieval (blue) and ECMWF reanalysis (red). Panel (a) represents the observations of the Quiliayute station (72 797, USA) at 00:00:00 UTC, 20 September 2009, and (b) represents the observations of Fuyang station (58 203, China) at 23:16:41 UTC, 6 April 2009.

\section{Possible causes of humidity sensor failure}

\subsection{Performance of the sensor}

Figure 7 shows the relative humidity and temperature profiles of six different failure sensors. As seen in the figures, the relative humidity observations decrease quickly in a short time from a high-humidity value to below $5 \%$ in the middle-lower troposphere, and they then maintain low-humidity values. For example, the German Graw G sensor decreases rapidly from 93 to $1 \%$ from a height of 820 to $787 \mathrm{hPa}$, and then maintains low-humidity values. Some sensors lose their sensing ability entirely (Fig. 7a and d), whereas other sensors recover. The relative humidity in all cases is over $87 \%$. When the relative humidity starts decreasing, an inversion temperature layer is observed, thus revealing the existence of clouds in these cases.

Figure 8 shows the geographical distribution of the operational radiosonde stations worldwide. The different colors represent different humidity sensors. In contrast to Fig. 2, all 

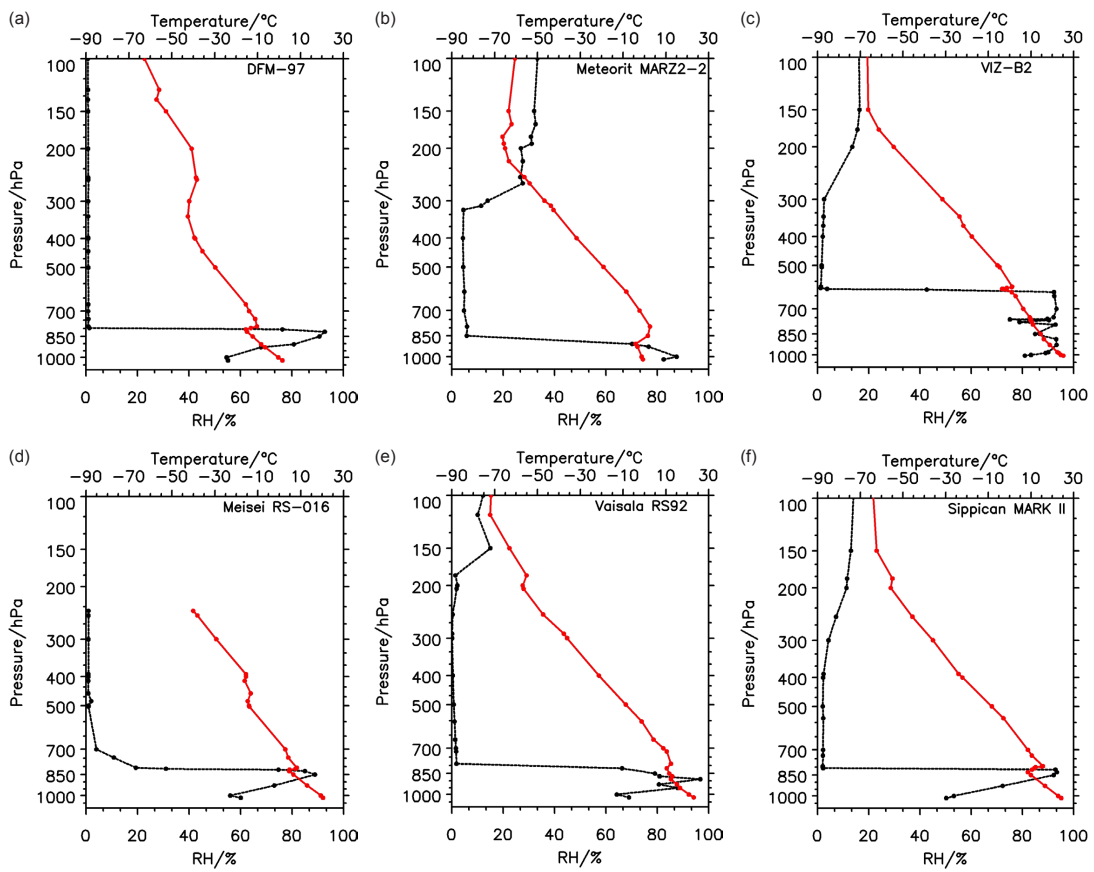

Figure 7. Relative humidity (black lines) and temperature (red lines) profiles for different types of radiosonde sensor: (a) DFM-97 (Gosan, Korea, $47185 ; 33.28^{\circ} \mathrm{N}, 126.15^{\circ} \mathrm{E}$ ) at 12:00 UTC (14 January 2009); (b) Meteorit MARZ2-type 2 (Kalac, Russian, 34247 ; 50.42 ${ }^{\circ}$, $41.05^{\circ} \mathrm{E}$ ) at 00:00 UTC (26 October 2009); (c) VIZ-B2 (Curacao, $78988 ; 12.12^{\circ} \mathrm{N}, 68.58^{\circ} \mathrm{W}$ ) at 12:00 UTC (17 December 2008); (d) Meisei RS-016 (Minamitorishima, Japan, $47991 ; 24.28^{\circ} \mathrm{N}, 153.98^{\circ}$ E) at 12:00 UTC (7 February 2009); (e) Vaisala RS92 (Galeao, Brazial, 83746 ; $22.82^{\circ} \mathrm{S}, 316.76^{\circ} \mathrm{E}$ ) at 12:00 UTC (21 May 2009); (f) US Sippican MARK II (Puerto Rico, 78 526; 18.42 ${ }^{\circ}$ N, 294.03 ${ }^{\circ}$ E) at $12: 00$ UTC (10 March 2009).

sensors are potential failures and most of them are carbon hygrometers. In the figure, the blue point represents the RS92 sensor, which is widely used in western Europe, Australia and South America. Although the RS92 uses capacitive hygrometers and is recognized as the best sensor, the number of failed observations is low, with an occurrence rate of approximately $3.5 \%$ per year. Therefore, instrument quality is not the only cause of sensor failure. However, the similarity between Figs. 8 and 2 indicates that instrument capability is always an important factor that should not be ignored. The capability of the Chinese L-band system is insufficient; hence, this sensor tends to exhibit serious problems.

\subsection{Relationship with atmospheric conditions, especially clouds}

Figure 9 presents the distribution of stratiform clouds and their temporal evolution from the International Satellite Cloud Climatology Plan D2 data sets (Rossow and Schiffer, 1999) in the corresponding period. A low cloud belt exists close to $30^{\circ}$ in the Northern Hemisphere and Southern Hemisphere, consistent with Klein and Hartmann's results (1993). From the above analysis, the failed relative humidity observations mainly occur at almost $30^{\circ}$ latitudes in both hemispheres, and are particularly obvious in winter. This may imply a connection between the failure of the humidity sensors and the distribution of stratiform clouds.

Generally, relative humidity is high inside stratiform clouds and low between two interbedded clouds; it decreases sharply at the top of clouds. The gradient of temperature stratification is close to that of the wet adiabatic process. The upper and top levels of the stratiform clouds usually have an inversion temperature layer that appears below the clouds at a height of $0.1-0.2 \mathrm{~km}$ away from the top of the clouds (Shi, 2005). The examples provided in Sect. 5.1 indicate that the relative humidity reported by all radiosondes is over $87 \%$ and that it decreases sharply with the existence of the inversion temperature layer (Fig. 7). This is caused by the radiosonde ascending through stratiform clouds.

Wang et al. (2003) found that the US Sippican sensor loses sensitivity and stops responding in cold temperatures (approximately below $-34{ }^{\circ} \mathrm{C}$ or above $8.5 \mathrm{~km}$ ), or when relative humidity significantly changes within a short time; we find similar phenomena in our study. However, they did not further analyze why relative humidity dramatically changes within a short time. From the above analysis, we think that the dramatic changes of relative humidity occur after the radiosonde goes through the stratiform clouds, especially given the wide range of stratiform clouds. It is also related to the inertia. When the radiosonde leaves a cloud, assuming that it 


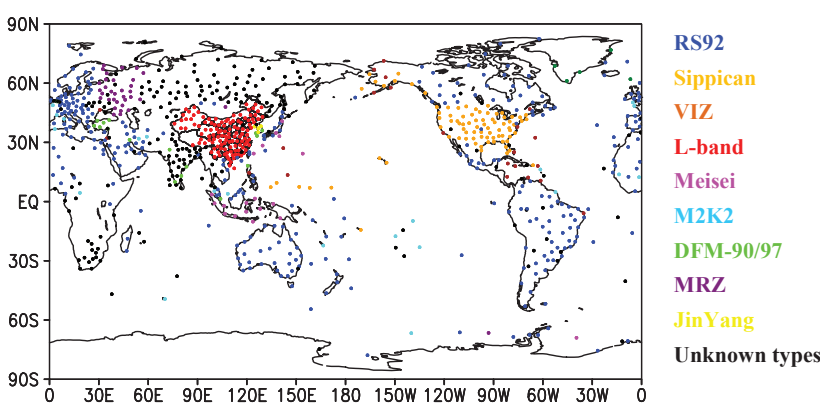

Figure 8. Geographical distribution of operational radiosonde sensor usage.

is from the dramatically wet-very dry environment, the humidity observation value might be reduced even less than the responsive range of sensor due to the inertia effect. The horizontal scale of stratiform clouds is tens to thousands of kilometers; thus, although the horizontal distribution of the atmosphere is relatively uniform and stable, the vertical distribution may exhibit dramatic changes. On the other hand, the horizontal scale of convective clouds is smaller; the lower humidity area is located inside cloud monomers. The radiosonde balloon drifts during ascent, it might repeatedly go through convective cloud monomers from the sides instead of the top. Therefore, the temperature and humidity profiles can neither depict the relatively uniform changes in the horizontal direction nor drastic changes in the vertical direction if the radiosonde balloon drifts in convective clouds. There are rich stratiform clouds in the subtropics, so the phenomena occur easily. But this is only an estimation, and needs proving in a lab experiment.

\section{Discussion and conclusion}

According to radiosonde data from December 2008 to November 2009, the problem of abnormally dry bias induced by radiosonde humidity sensor failure in the low and midtroposphere was studied. We calculated the percentage of failures and compared them with other satellite products and analysis data. This allowed us to analyze the possible causes. The main conclusions are as follows:

1. In the middle and lower troposphere, the very thick dry layer is often observed from operational radiosonde humidity observations. The phenomenon is common. However, it is different from the dry layer in the natural atmospheric variability, which also exists in the troposphere, especially in the subtropics and extratropics, based on previous studies. One of the most obvious features is that the relative humidity in our study changes less with time and maintains a very low value in a thick atmospheric layer, indicating that the sensor fails to respond to the variation of the atmosphere. Globally, the annual average occurrence percentage of such

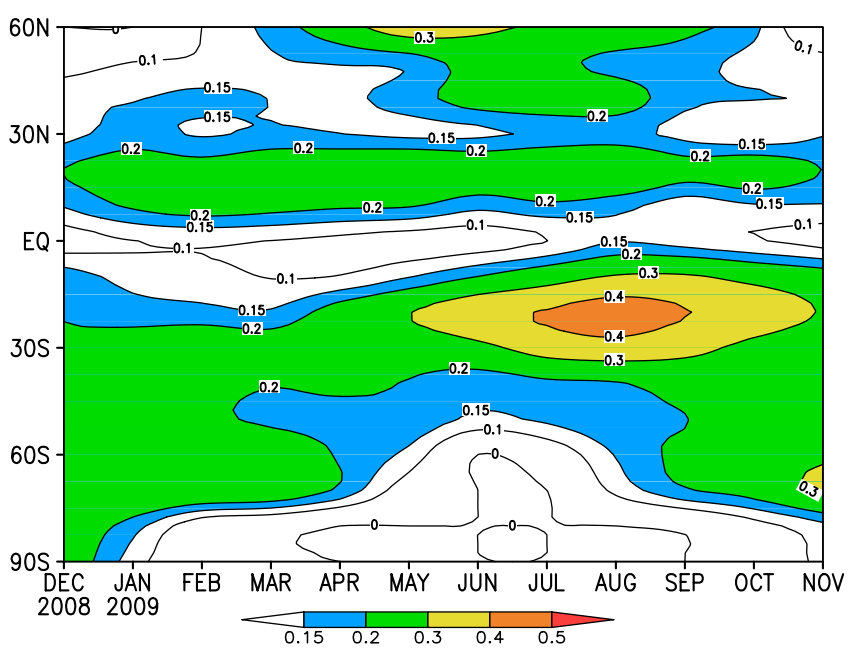

Figure 9. Average longitudinal distribution of stratiform clouds and their temporal evolution from December 2008 to November 2009, unit: 1 .

dry humidity observations is approximately $4.2 \%$, and these observations mainly occur between the heights of 700 and $450 \mathrm{hPa}$ at 20 to $40^{\circ}$ latitudes in the Northern Hemisphere and Southern Hemisphere. The percentage is high, especially in winter, reaching $9.53 \%$ in the middle latitudes of the Northern Hemisphere and $16.82 \%$ in the middle latitudes of the Southern Hemisphere.

2. The reasons behind the extremely low relative humidity observations in the low and middle troposphere relate to the performance of the radiosonde humidity sensor and the cloud types in the atmosphere. When the radiosonde ascends through deep stratiform clouds with high moisture content, due to the huge changes in the external atmospheric conditions, the humidity sensor fails to adapt and stops responding. The dramatic change of relative humidity in a short time further reveals the possible variation of the atmospheric state. However, the internal physical mechanism of the humidity sensor failure requires further investigation.

3. The low relative humidity data that satisfy the criteria proposed by Tang et al. (2014) are erroneous. These data do not represent the real atmosphere. However, they have been archived as formal records, and are widely used in atmospheric science research and services. If the data are used prior to correction and quality control, the reliability of weather prediction and climate analysis will be adversely affected. Therefore, there is an urgent need to correct these erroneous data, or flag the faulty data before ending up in the radio sounding archives in the future.

Edited by: P. Stammes 


\section{References}

Anthes, R. A., Bernhardt, P. A., Chen, Y., Cucurull, L., Dymond, K. F., Ector, D., Healy, S. B., Ho, S. P., Hunt, D. C., Kuo, Y.-H., Liu, H., Manning, K., McCormick, C., Meehan, T. K., Randel, W. J., Rocken, C., Schreiner, W. S., Sokolovskiy, S. V., Syndergaard, S., Thompson, D. C., Trenberth, K. E., Wee, T. K., Yen, N. L., and Zeng, Z.: The COSMIC/FORMOSAT-3 Mission-Early results, B. Am. Meteorol. Soc., 89, 313-333, 2008.

Bian, J., Chen, H., Vömel, H., Duan, Y., Xuan, Y., and Lv, D.: Intercomparison of humidity and temperature sensors: GTS1, Vaisala RS80, CFH, Adv. Atmos. Sci., 28, 139-146, 2011.

Dee, D. P., Uppala, S. M., Simmons, A. J., Berrisford, P., Poli, P., Kobayashi, S., Andrae, U., Balmaseda, M. A., Balsamo, G., Bauer, P., Bechtold, P., Beljaars, A. C. M., Berg, L. van de, Bidlot, J., Bormann, N., Delsol, C., Dragani, R., Fuentes, M., Geer, A. J., Haimberger, L., Healy, S. B., Hersbach, H., Hólm, E. V., Isaksen, L., Kållberg, P., Köhler, M., Matricardi, M., McNally, A. P., Monge-Sanz, B. M., Morcrette, J. J., Park, B. K., Peubey, C., Rosnay, P. de, Tavolato, C., Thépaut, J.-N., and Vitart, F.: The ERA-Interim reanalysis: configuration and performance of the data assimilation system, Q. J. Roy. Meteorol. Soc., 137, 553-597, 2011.

Klein, S. A. and Hartmann, D. L.: The seasonal cycle of low stratiform clouds, J. Climate, 6, 1587-1606, 1993.

Li, F., Li, B., and Wu, L.: An introduction of WMO 8th radiosondes inter-comparison and integrated remote instruments experiment, Adv. Earth Sci., 27, 916-924, 2012 (in Chinese).

Li, W., Xing, Y., and Ma, S. Q.: The analysis and comparison between GTS1 radiosonde made in China and RS92 Radiosonde of Vaisala company, Meteorological monthly, 35, 97-102, 2009 (in Chinese).

Miloshevich, L. H., Vömel, H., Whiteman, D., Lesht, B., Schmidlin, F. J., and Russo, F: Absolute accuracy of water vapor measurements from six operational radiosonde types launched during AWEX-G and implications for AIRS validation, J. Geophys. Res., 111, D09S10, doi:10.1029/2005JD006083, 2006.

Nash, J., Oakley, T., Vömel, H., and Li, W.: WMO intercomparison of high quality radiosonde systems, World Meteorol. Org., Yangjiang, China, Tech. Rep., 2010.

Rossow, W. B. and Schiffer, R. A.: Advances in Understanding Clouds from ISCCP, B. Am. Meteorol. Soc., 80, 2261-2288, 1999.

Shi, A.: Progress in researches on microphysical characteristics and precipitation mechanisms of stratiform cloud precipitation, Meteorological Science and Technology, 2, 104-108, 2005 (in Chinese).
Spencer, R. W. and Braswell, W. D.: How dry is the tropical free troposphere? Implications for global warming theory, B. Am. Meteorol. Soc., 78, 1097-1106, doi:10.1175/15200477(1997)078<1097:HDITTF>2.0.CO;2, 1997.

Sun, B., Reale, A., Seidel, D. J., and Hunt, D. C.: Comparing radiosonde and COSMIC atmospheric profile data to quantify differences among radiosonde types and the effects of imperfect collocation on comparison statistics, J. Geophys. Res., 115, D23104, doi:10.1029/2010JD014457, 2011.

Tang, N., Liu, Y., Li, G., and Li, F.: Preliminary analysis on abnormally dry phenomena of relative humidity observations of the Chinese L-band radiosonde system, J. Trop. Meteorol., 30, 643-653, 2014 (in Chinese).

Vömel, H., Selkirk, H., Miloshevich, L., Valverde-Canossa, J., Valdés, J., Kyrö, E., Kivi, R., Stolz, W., Peng, G., and Diaz, J. A.: Radiation dry bias of the Vaisala RS92 humidity sensor, J. Atmos. Ocean. Tech., 24, 953-963, 2007.

Wang, J. H., Cole, H. L., Carlson, D. J., Miller, E. R., Beierle, K., Paukkunen, A., and Laine, T. K.: Corrections of humidity measurement errors from the Vaisala RS80 radiosonde - application to TOGA COARE data, J. Atmos. Ocean. Tech., 19, 981-1002, 2002.

Wang, J. H., David, J. C., David, B. P., Terrence, F. H., Dean, L., Harold, L. C., Kathryn, B., and Edward, C.: Performance of operational radiosonde humidity sensors in direct comparison with a chilled mirror dew-point hygrometer and its climate implication, Geophys. Res. Lett., 30, 1860, doi:10.1029/2003GL016985, 2003.

Wang, J. H., Zhang, L. Y., Lin, P. N., Mark, B., Harold, C., Jack, F., Terry, H., Dean, L., Scot, L., Charlie, M., Joseph, V., Weng, C.-H., and Kathryn, Y.: Water vapor variability and comparisons in the subtropical Pacific from The Observing System Research and Predictability Experiment-Pacific Asian Regional Campaign (T-PARC) Driftsonde, Constellation Observing System for Meteorology, Ionosphere, and Climate (COSMIC), and reanalyses, J. Geophys. Res., 115, D21108, doi:10.1029/2010jd014494, 2010.

WMO-NO: Guide to Meteorological Instruments and Methods of Observation, 2008 Edn. (7TH), updated in 2010, Geneva, 2012.

Wolfgang, S., Claude, H., Schönenborn, F., Leiterer, U., Dier, H., and Lanzinger, E.: Pressure and temperature differences between Vaisala RS80 and RS92 radiosonde systems, J. Atmos. Ocean. Tech., 25, 909-927, 2008.

Zhang, C. and Chen, J.: Contrast analysis of data observed by 59type and L-band sonde, Journal of Shanxi Meteorology, 1, 29-31, 2010 (in Chinese).

Zhang, C. D., Mapes, B. E., and Soden, B. J.: Bimodality in tropical water vapour, Q. J. Roy. Meteorol. Soc., 129, 2847-2866, doi:10.1256/qj.02.166, 2003. 